\title{
Celiac Disease: Internet Resources
}

\section{Brian D. Cameron}

Ryerson University

\section{digital.library.ryerson.ca/object/315}

\section{Please Cite:}

Cameron, B. D. (2002). Celiac disease: Internet resources. Health Care on the Internet, 6(3), 23-32.

doi:10.1300/J138v06n03 03

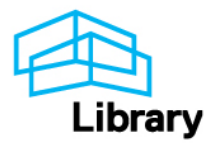




\title{
Celiac Disease: Internet Resources
}

\author{
Brian D. Cameron
}

\begin{abstract}
Celiac disease is an autoimmune malabsorption disorder caused by gluten, the protein present in wheat, rye, and barley. Gluten destroys the absorptive layer of the small intestine, which leads to malnourishment and other serious diseases. Recent research has established that celiac disease is a common disorder, affecting 1 in every 120 to 300 people in North America and Europe. The only therapy is adherence to a completely gluten-free diet for life. This article reviews a number of Internet resources that are essential in assisting celiacs to live a normal life.
\end{abstract}

KEYWORDS. Celiac disease, coeliac disease, celiac sprue, gluten intolerance, Internet resources

Author. Brian Cameron, MA, MLS (bcameron@ @yerson.ca) is a Reference Librarian and Co-manager, Systems, Access Services Department, Ryerson University Library, 350 Victoria Street, Toronto, Ontario M5B 2K3. Currently, he is the Reviews Editor for the Journal of Hospital Librarianship. He has served as President of the Toronto Health Libraries Association and has served on the Board of Directors of the Canadian Health Libraries Association. 


\section{INTRODUCTION}

Celiac Disease, also known as Gluten-induced Enteropathy, Gluten-sensitive Enteropathy, Celiac Sprue, or Nontropical Sprue, is a genetically-inherited intestinal malabsorption disorder caused by gluten, the protein present in wheat, rye, barley, and possibly oats. ${ }^{1-2}$ Recent research has determined that two gliadin fractions of gluten cause an immune response, ${ }^{3}$ resulting in severe damage to the small intestine. The villi, or finger-like structure of the small intestine, are flattened, leading to malabsorption, malnourishment, and other life-threatening diseases.

Persons with celiac disease have a significantly higher incidence of certain types of cancer ${ }^{4}$ and are at higher risk for developing other auto-immune disorders, especially diabetes. ${ }^{5}$ As many as twelve other disorders, such as dermatitis herpetiformis, spinocerebellar ataxia, and epilepsy, have been linked to celiac disease. ${ }^{6-7}$

Published rates of prevalence of celiac disease vary significantly. It has generally been considered to be a rare disease in North America, with a prevalence of 1 in 10,000. By contrast, the incidence in the United Kingdom has been estimated at 1 in $300 .{ }^{8}$ However, recent mass-screenings in the United States suggest that celiac disease is a common disorder in both the United Stated and Europe, affecting as many as 1 of every 120 to 300 persons. $^{9}$

Blood tests can screen for antiendomysial or antigliadin antibodies, present in $70 \%$ to $90 \%$ of celiac patients, but a biopsy of the distal duodenum or proximal jejunum remains the gold standard, and is the only definitive means of achieving a diagnosis. Because many medical professionals are unaware of celiac disease, or consider it to be a rare disorder, celiac disease remains both an under-diagnosed disorder ${ }^{10}$ and a 
misdiagnosed disorder. ${ }^{11}$ The Canadian Celiac Association's national survey found that the following disorders were diagnosed prior to the correct diagnosis of celiac disease: anemia, stress, nervous condition, irritable bowel syndrome, gastric ulcer, food allergy, colitis, menstrual problems, edema, gallstones, and diverticulitis. ${ }^{12}$

The only treatment for celiac disease is the adherence to a completely gluten-free diet for life. The widespread use of gluten in commercially prepared foods makes this an extremely difficult chore. Food labeling legislation does not compel manufactures to list the ingredients of food additives. As a result, celiacs must be cautious of any food additive, especially ingredients such as natural flavoring, hydrolyzed vegetable and plant proteins, and modified starches. Contamination in the manufacturing process is another major concern, as is the use of wheat flour as an anti-caking agent and on conveyor belts in the production of potato chips and other foods.

The Internet has become a popular medium for sharing information about food, and for giving and receiving support. This article reviews a number of quality internet resources related to celiac disease.

\section{ORGANIZATIONS}

\section{Celiac Disease Foundation (CDF)}

\section{<http://www.celiac.org/>}

The Celiac Disease Foundation (CDF) is a non-profit organization offering support and assistance to people suffering from celiac disease and dermatitis herpetiformis. The association works with health professionals to promote clinical 
research and improve care, and it sees itself as a "link between clinical research and patient care." CDF assisted in the formation of the Celiac Disease Standardization Group (CDSG), a sub-group of CDF comprised of international experts, for the purpose of "establishing educational goals and collaborating on a standard for the entire diagnostic process of CD." The Web site contains important information on causes, symptoms, diagnosis, and treatment. Some regional links are provided in addition to partial full-text of its newsletter.

\section{Gluten Intolerance Group (GIG)} <http://www.gluten.net/>

The Gluten Intolerance Group (GIG) is a non-profit organization dedicated to increasing awareness of celiac disease by providing accurate and up-to-date information, education, and support to those with celiac disease and dermatitis herpetiformis. The quarterly newsletter contains book reviews, research summaries, as well as recipes and association news and events. GIG also provides educational materials, such as patient packages, and runs a Kids' Camp. The site contains information on symptoms, diagnosis, treatment, prognosis, diet, and related disorders.

\section{The Celiac Sprue Association/United States of America, Inc. (CSA/USA)}

\section{<http://www.csaceliacs.org/>}

The Celiac Sprue Association/United States of America (CSA/USA) is a nonprofit organization with the purpose of providing information and referral services for people suffering from celiac disease and/or dermatitis herpetiformis. The site contains 
information suitable for health care professionals and it is rich in resources for consumers. Information about the disease and details about appropriate foods, medications, as well as some recipes are provided. CSA/USA also offers an extensive library of articles related to the disorder, and publishes a newsletter.

\section{Friends of Celiac Disease Research, Inc. <http://www.friendsofceliac.com/>}

Friends of Celiac Disease Research is a non-profit, charitable organization founded in 1999 to help promote research, education, and awareness of celiac disease. It publishes a brochure for non-celiacs, funds a national awareness campaign, and holds fundraising events. The Web site provides information about the disease, offers links to quality resources and support groups, and solicits donations to support research activities.

\section{Canadian Celiac Association}

$<$ http://www.celiac.ca/>

The Canadian Celiac Association offers support and information to celiacs and health care professionals in English and French. Its mission is founded on "awareness, advocacy, education and research." It administers research awards that are offered to medical professionals. Information about the disease and the appropriate diet is provided on the website, along with a listing of books, pamphlets, videos, and other merchandise, published by the Association. 


\section{Other Associations}

Many other national celiac associations maintain a Web presence for the purposes of providing support and information to celiacs. A few other examples are: Coeliac UK $<$ http://www.coeliac.co.uk/>, Coeliac Society of Ireland <http://www.coeliac.ie/>, The Coeliac Society of Australia <http://www.coeliac.org.au/>, and The Austrian Coeliac Society <http://members.kabsi.at/zoeliakie/>.

\section{RESEARCH}

\section{Coeliac Disease Study Group} <http://www.uta.fi/ Ilmama/cdstudy/>

Based in Finland, the Coeliac Disease Study Group is actively engaged in research on celiac disease, particularly, "clinical presentation of the disease, serological screening tests and on coeliac disease epidemiology." Most research is conducted by the University of Tampere, through the Tampere University Hospital. A complete list of publications is available, including articles submitted, but not yet published. The University is a major hub of celiac research, and several Ph.D. theses have been written by doctoral students at the University.

\section{Center for Celiac Research - University of Maryland $<$ http://celiaccenter.org/>}

The Center for Celiac Research's aim is to increase awareness of celiac disease, to support research, and to foster quality education for doctors and students. The Center is currently conducting research in three major areas: multi-center serological screening to 
determine the prevalence of celiac disease in the United States; development of a noninvasive diagnostic test for $\mathrm{CD}$; and, a new dot-blot assay. Its preliminary findings suggest that as many as 1 in 150 Americans may be afflicted with celiac disease.

\title{
OVERVIEW SITES
}

\section{National Institutes of Health - National Digestive Diseases Information}

\section{Clearinghouse}

<http://www.niddk.nih.gov/health/digest/pubs/celiac/index.htm>

This NIH site offers an excellent introduction to celiac disease. Symptoms, diagnosis, treatment - including a chart of foods to eat and avoid - and associated conditions are clearly described. Persons requiring additional information are directed to a list of additional quality sites.

\section{Merck Manual of Diagnosis and Therapy, Section 3, Chapter 30: Malabsorption Syndromes: Celiac Disease <http://www.merck.com/pubs/mmanual/section3/chapter30/30c.htm>}

The Merck Manual's description of celiac disease is comprehensive without being overly technical. It provides a solid description of the condition along with a discussion of prognosis and treatment.

\author{
Mayo Clinic \\ $<$ http://www.mayoclinic.com/>
}


The Mayo Clinic's A-Z listing of diseases and conditions offers a wealth of easily-understandable information on a wide array of medical conditions. The celiac disease page offers a thorough description of the disease, including signs and symptoms, causes, risk factors, diagnosis, treatment, and coping.

\section{Celiac Disease: A Guide for Children and Their Families - North American Society for Pediatric Gastroenterology, Hepatology, and Nutrition (NASPGHAN) <http://www.naspgn.org/sub/celiac_disease.asp> \\ NASPGHAN's overview of celiac disease is designed for families. Useful features include a glossary, a description written for children, a listing of appropriate food companies, and some recommended books.}

\section{Celiac Disease: Patient Handout. American Academy of Family Physicians <http://www.familydoctor.org/handouts/236.html>}

Familydoctor.org is a service of the American Academy of Family Physicians. This handout on celiac disease is a very basic description of the disorder. It serves as a good introduction therapy and provides a list of essential resources.

\section{Detecting Celiac Disease in Your Patients} <http://www.aafp.org/afp/980301ap/pruessn.html>

This indispensable article (Pruessner HT. "Detecting Celiac Disease in Your Patients." American Family Physician 57(March 1998): 1023-34, 1039-41.) is designed to assist physicians in the diagnosis of celiac disease. It argues that the disease is under 
diagnosed, and reviews prevalence, pathogenesis, clinical presentation, associated diseases, diagnosis, and treatment.

\section{METASITES}

\section{MEDLINEplus Health Information}

\section{<http://www.nlm.nih.gov/medlineplus/celiacdisease.html>}

MEDLINEplus Health Information is probably the best consumer health site on the internet. It provides information on a wide array of health topics, drug information, dictionaries, directories, and access to MEDLINE. Consumers are directed to quality Internet resources on celiac disease, which include the best description and disease management sites, and appropriate associations. A very useful feature is the "Latest News" category.

\section{Medical Matrix}

<http://www.medmatrix.org/reg/login.asp>

Medical Matrix's peer-reviewed clinical resources are annotated and ranked by physicians and medical librarians. The site requires free registration. Medical Matrix is an important gateway to quality Web-based resources.

\section{Celiac.com: Celiac Disease \& Gluten-Free Diet Support Page <http://www.celiac.com> \\ Celiac.com is a very large and essential site for information and links to web resources on celiac disease and dermatitis herpetiformis. Although the site is not}


maintained by a medical professional, there is an enormous amount of quality information, including articles, synopses of medical articles, an FAQ, a history of the disease, as well as information about foods and associated disorders. A message board, recipes, events, a comprehensive listing of links, and a wealth of other information is provided. It is worth keeping in mind that this site is partnered with the GlutenFreeMall $<$ http://www.glutenfreemall.com/>, a commercial portal through which consumers can shop for a variety of specialty food products.

\section{Celiac Disease Webring} <http://j.webring.com/webring?ring=celiac;list >

The Webring contains links to dozens of sites devoted to some aspect of celiac disease. This site should be used with caution, because anyone can link his/her site, and those sites contained are of variable quality. The ring also contains a number of businesses that sell gluten-free products. Nevertheless, it is a good starting point for celiac disease resources on the Web.

\section{SUPPORT GROUPS}

\section{Celiac-Celiac/Coeliac Wheat/Gluten-Free List <http://maelstrom.stjohns.edu/archives/celiac.html>}

Since 1994, this list has helped celiacs and family members share information and cope with the disorder. This list is well managed. Summarization is supported and extraneous chat is kept to a minimum. The archives are fully searchable. 


\section{Cel-Kids - Celiac/Coeliac Wheat/Gluten-Free Children List <http://maelstrom.stjohns.edu/archives/cel-kids.html>}

This unmoderated listserv is designed for parents who are raising celiac children. Parents can offer support and exchange recipes and information about foods.

\section{Celiac-Canada}

<http://www.penny.ca/Celiac-canada.htm>

Celiac Canada is a an important list for the exchange of information about Canadian food companies, medical professionals, stores, and restaurants. Canadian celiacs and those visiting Canada will find this group useful. The Web site contains the archives as well as gluten-free product lists and a travel guide for Canada.

\section{alt.support.celiac}

Google's recently-assembled complete Usenet archive offers a wealth of information on celiac disease. Participation is now possible without a Usenet News feed and newsreader, through Google Groups <http://groups.google.com/>

\section{Yahoo! Groups \\ <http://groups.yahoo.com> \\ Many celiac and gluten-free groups are listed at Yahoo! Groups. Search for "celiac" or "gluten" to find them. These groups offer support by means of information sharing and recipe exchanges. Members can search the archives on the Yahoo! site.}




\section{SUPPORT GROUPS FOR CHILDREN}

\section{Club Celiac}

<http://www.geocities.com/EnchantedForest/Glade/2715/clubceliac.htm>

Club Celiac is designed for children to exchange recipes and information exchanges through a mailing list or chat room. The site also contains recipes, food lists, and important information about celiac disease.

\section{CONCLUSION}

Rather than being a rare disorder, celiac disease may be the world's most commonly-inherited genetic disorder. As more people are diagnosed, the internet is becoming an indispensable resource for people requiring information and support. The Internet offers many reliable Web sites on celiac disease, as well as a number of important support groups.

The Web sites selected for this paper offer credible information on celiac disease and dermatitis herpetiformis. As usual, consumers should be aware that inaccurate information is common on the Internet. It is essential that consumers consult a physician if they believe that they may have celiac disease or are concerned about other health issues.

Received: February 19, 2002

Accepted: February 28, 2002 


\section{REFERENCES}

1. Janatuinen, E.K.; Kemppainen, T.A.; Pikkarainen, P.H.; et al. "Lack of Cellular and Humoral Immunological Responses to Oats in Adults with Coeliac Disease." Gut 46(March 2000): 327-31.

2. Branski, D., and Shine, M. "Oats in Celiac Disease.” New England Journal of Medicine 334(March 28, 1996): 865-6.

3. Anderson, R.P.; Degano, P.; Godkin, A.J.; et al. "In Vivo Antigen Challenge in Celiac Disease Identifies a Single Transglutaminase-Modified Peptide as the Dominant A-gliadin T-cell Epitope.” Nature Medicine 6(March 2000): 337-42.

4. Biagi, F.; Lorenzini, P.; and Corazza G.R. "Literature Review on the Clinical Relationship Between Ulcerative Jejunoileitis, Coeliac Disease, and Enteropathyassociated T-cell." Scandinavian Journal of Gastroenterology 35(August 2000): 785-90.

5. Holmes, G.K. “Coeliac Disease and Type 1 Diabetes Mellitus - The Case for Screening." Diabetic Medicine 18(March 2001): 169-77.

6. Collin, P.; Kaukinen, K.; and Maki, M. "Clinical Features of Celiac Disease Today." Digestive Diseases 17(1999): 100-6.

7. James, M.W., and Scott, B.B. "Coeliac Disease: The Cause of the Various Associated Disorders?." European Journal of Gastroenterology \& Hepatology 13(September 2001): 1119-21.

8. Fasano, A., and Catass, C. "Current Approaches to Diagnosis and Treatment of Celiac Disease: An Evolving Spectrum.” Gastroenterology 120(2001): 636-51. 
9. Farrell, R.J., and Kelly, C.P. “Celiac Sprue.” New England Journal of Medicine 346(January 17, 2002): 180-8.

10. Farrell, R.J., and Kelly, C.P. “Diagnosis of Celiac Sprue.” American Journal of Gastroenterology 96(December 2001): 3237-46.

11. Dickey, W., and McConnell, J.B. "How Many Hospital Visits Does It Take Before Celiac Sprue is Diagnosed?” Journal of Clinical Gastroenterology 23(July 1996):21-3.

12. Davidson, A.G., and Campbell, J.A. "Celiac Disease and Dermatitis Herpetiformis. National Survey Indicates Delays in Diagnosis." Canadian Family Physician 38(1992): 2604-8. 